\title{
Strength calculation of frame structure of high-performance low speed diesel engine
}

\author{
Guixin Wang ${ }^{1}$, Dongyu Xing ${ }^{1, a}$ Xiaobo $\mathrm{Li}^{1}$ and Xiaoxiao $\mathrm{Niu}^{2}$ \\ ${ }^{1}$ College of Power and Energy Engineering, Harbin Engineering University, Harbin 150001, China \\ ${ }^{2}$ Henan Diesel Engine Industry CO.LTD, Luoyang 471003, China
}

\begin{abstract}
Finite element analysis software is used in this paper to analyze the strength of frame of high-performance low-speed diesel engine. Firstly, the former structure, single-butterfly plate, was changed into a new one, double-butterfly plate. Then, the finite element models were built, and the stress and deformation charts of these two structures under the maximum side thrust were calculated. As a result, we can see the strength and rigidity of the entire frame and guide is enough. And the ability of anti-deformation of double-butterfly plate is better than that of single-butterfly plate.
\end{abstract}

Keywords: engine block; finite element method; structural design; strength.

\section{Introduction}

The structure of engine block subassembly is complex. It is the main support of two-stroke diesel engines, and it is mostly used to support and fix all the parts in diesel [1]. The force situation of the engine block is complex because not only are the bolt pretightening force and interference force applied on it, but also other pressure such as gas pressure, reciprocating inertia force and lateral force on the piston, are also influencing the engine when it is working [2,3]. As for frames, except for assembly force, pressure of crosshead is also applied on it, and this is the main force on the frame. In this paper, finite element analysis was performed in different kinds of frames to calculate lateral force's effect on the strength and rigidity of frame under different crank angle.

\section{Finite element model and boundary conditions}

In the first place, we need to compare these two different frame structures. In the former frame structure, single-butterfly plate is used for supportive, and through bolts are set on the both sides of the butterfly plate in order to connect the cylinder block, frame and engine base. The 3D model is shown in figure 1 .

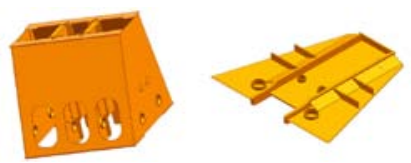

Figure 1. Former frame structure

a Corresponding author : 469149586@qq.com 
Butterfly plate is the main support plate of the frame, and many holes were drilled on it, which can have an influence on its ability to bear the weight. What is more, high coaxiality of the bearing block holes on the frame and engine base is required $[4,5,6]$. After taking into account all the abovementioned factors, a new frame structure was designed.
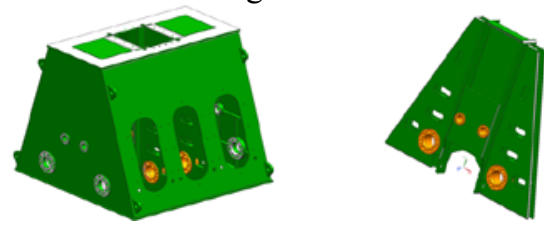

Figure 2. Improved frame structure

Single-butterfly plate was replaced by double-butterfly plate in the improved frame structure. The length of through bolts were halved because of space limit, and diameters of the bolts are increased. The improved frame structure is shown in figure 2.

The chart of crosshead's lateral force could be obtained after dynamic calculation, and it is the force boundary condition needed in the analysis $[7,8]$. The lateral force is shown in figure 3 .

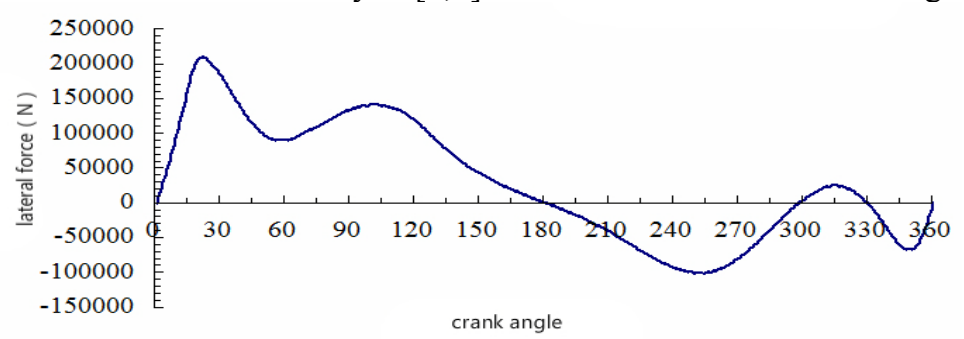

Figure 3. Lateral force of the Crosshead

There are two representative crank angles, $21^{\circ} \mathrm{CA}$ before TDC and $72{ }^{\circ} \mathrm{CA}$ after BDC. Stress and deformation distribution were calculated under these two situations.

\section{Comparison and analysis of frame's strength and deformation}

\section{$3.121^{\circ} \mathrm{CA}$ before TDC}

Distribution of deformation of these two structures are shown in figure 4.
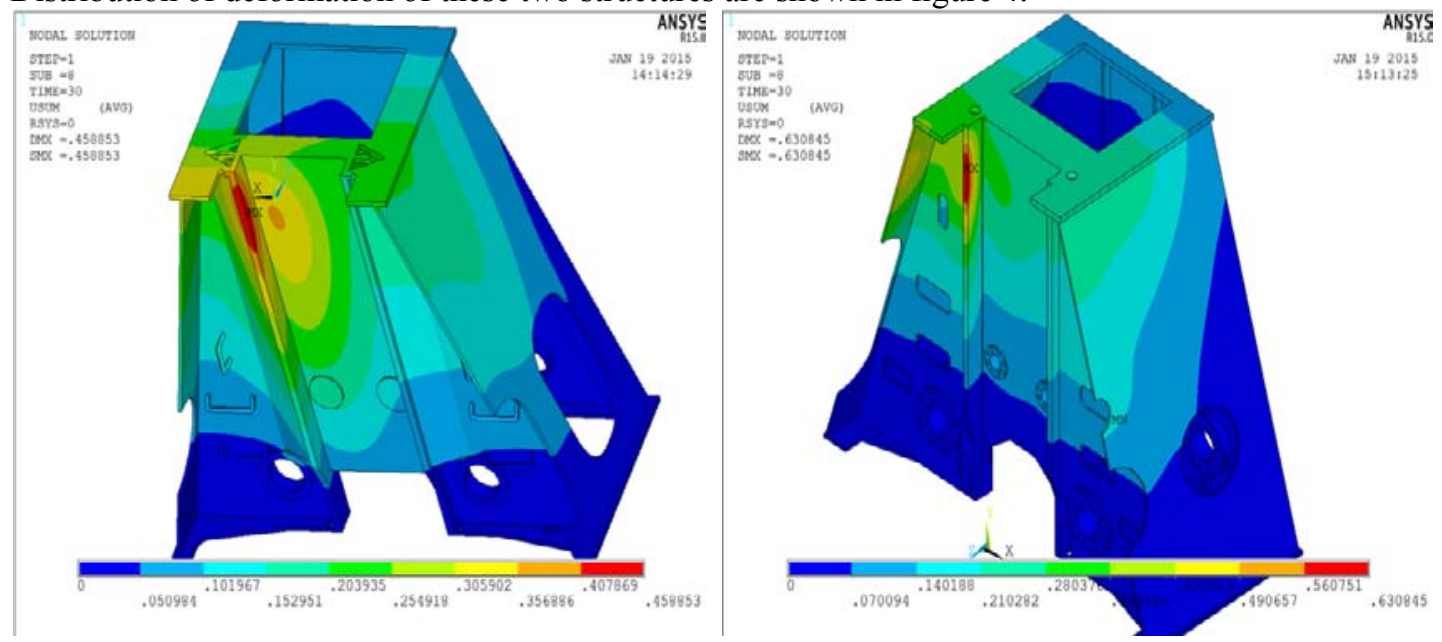

Figure 4. Comparison of deformation distribution of different frame structures 
At this moment, the distribution is similar. However, there are also some differences. Firstly, the area of deformation in the single-butterfly plate structure is larger. Secondly, the maximum deformation in the latter structure is larger for about $0.18 \mathrm{~mm}$.

Distribution of stress of these two structures are shown in figure 5.
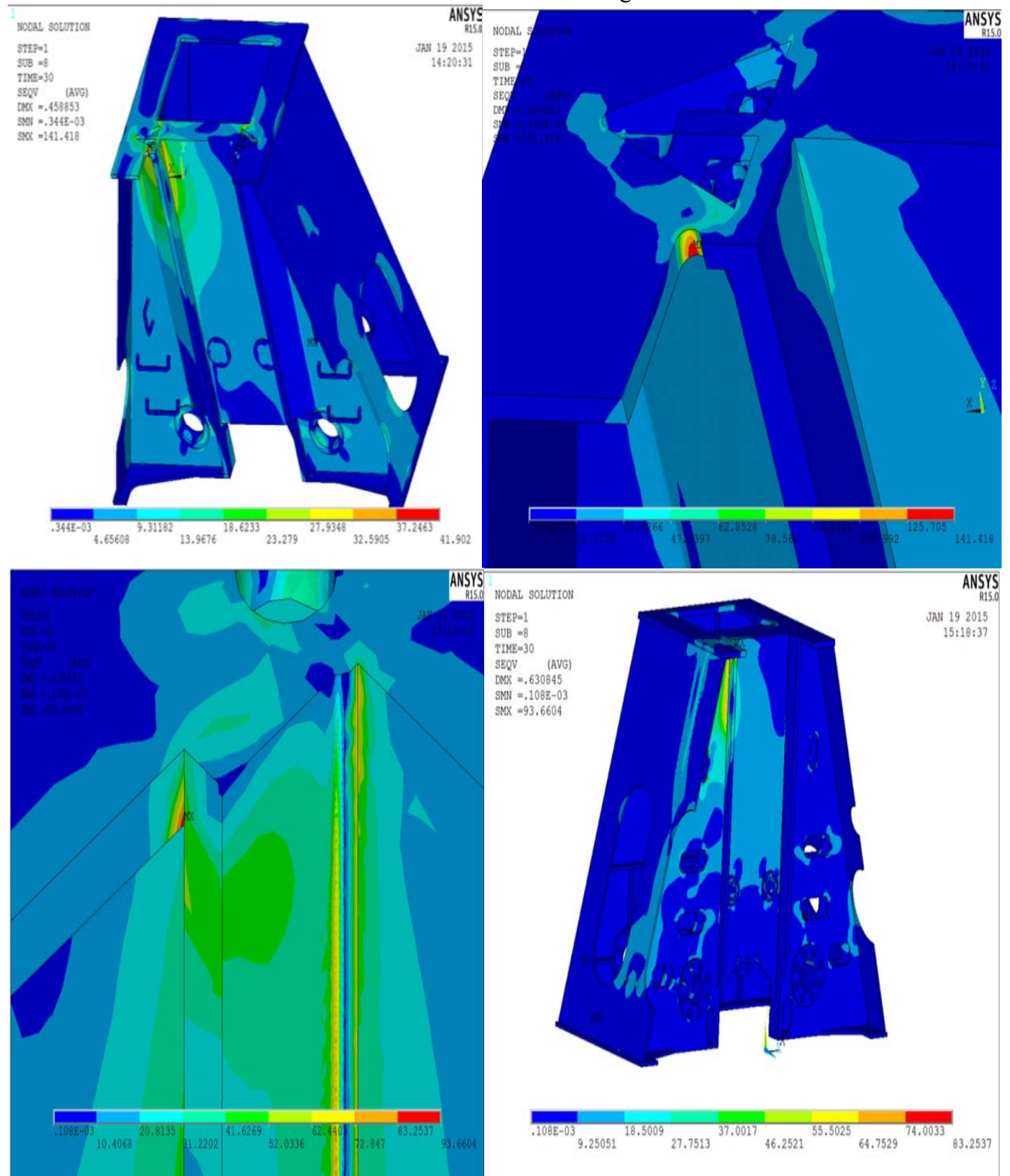

Figure 5. Comparison of stress distribution of different frame structures

As shown in the figures, stress concentration appears at the same region in two structures, but the area of the region and the stress value are different. The area and value of the former structure are both larger, while the maximum stress is $48 \mathrm{MPa}$ larger than the latter one. This indicates double-butterfly plate can enhance the frame's strength to a certain extent. 


\section{$3.272^{\circ} \mathrm{CA}$ after $\mathrm{BDC}$}

Distribution of deformation of these two structures at $72^{\circ} \mathrm{CA}$ after BDC are shown in figure 6 .

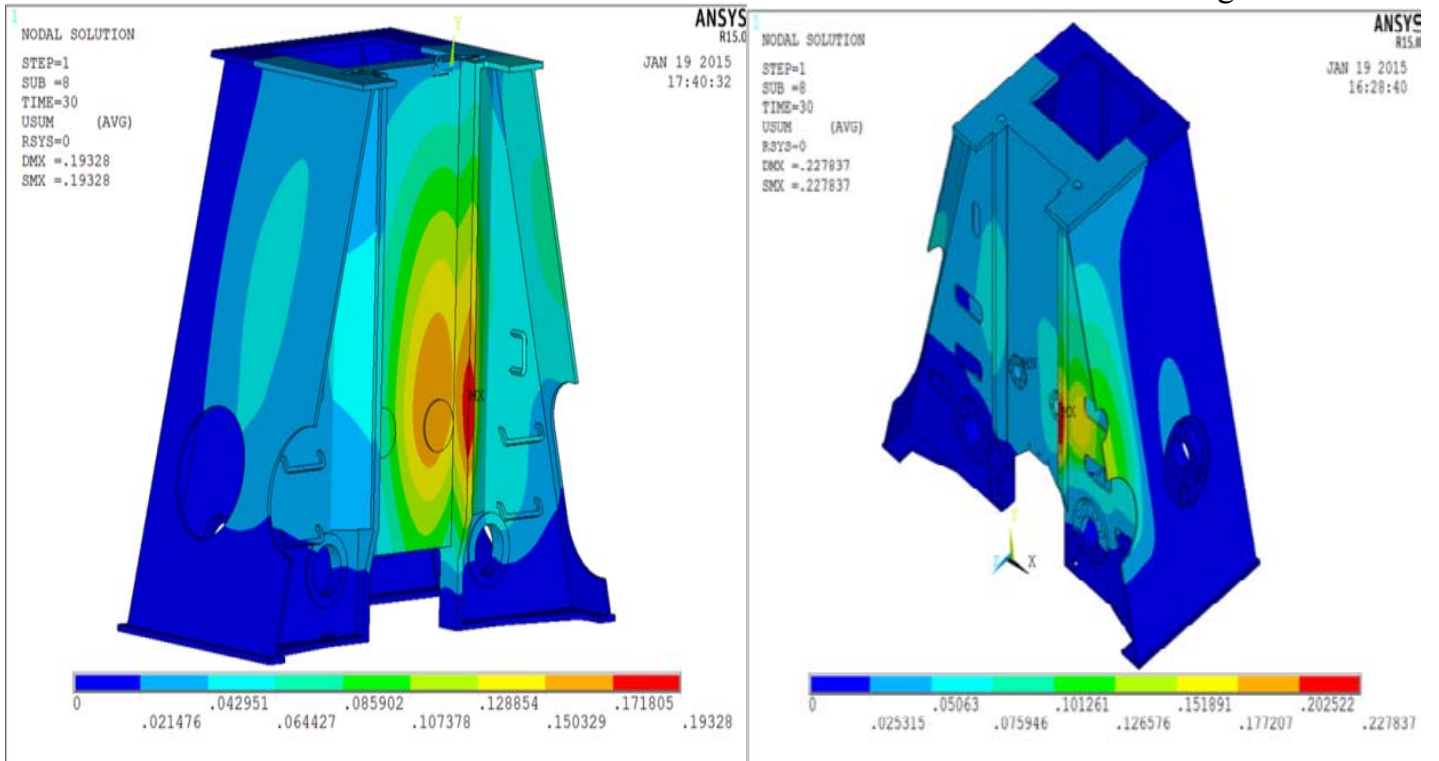

Figure 6. Comparison of deformation distribution of different frame structures

The deformation distribution is similar and the maximum deformation appears on the outermost side of the plate. The area of deformation in the single-butterfly plate structure is larger than double-butterfly plate structure. This is because the bearing capacity of the latter structure is enhanced due to the usage of double-butterfly plate. The maximum deformation in the latter structure is larger than the former one for about $0.034 \mathrm{~mm}$.

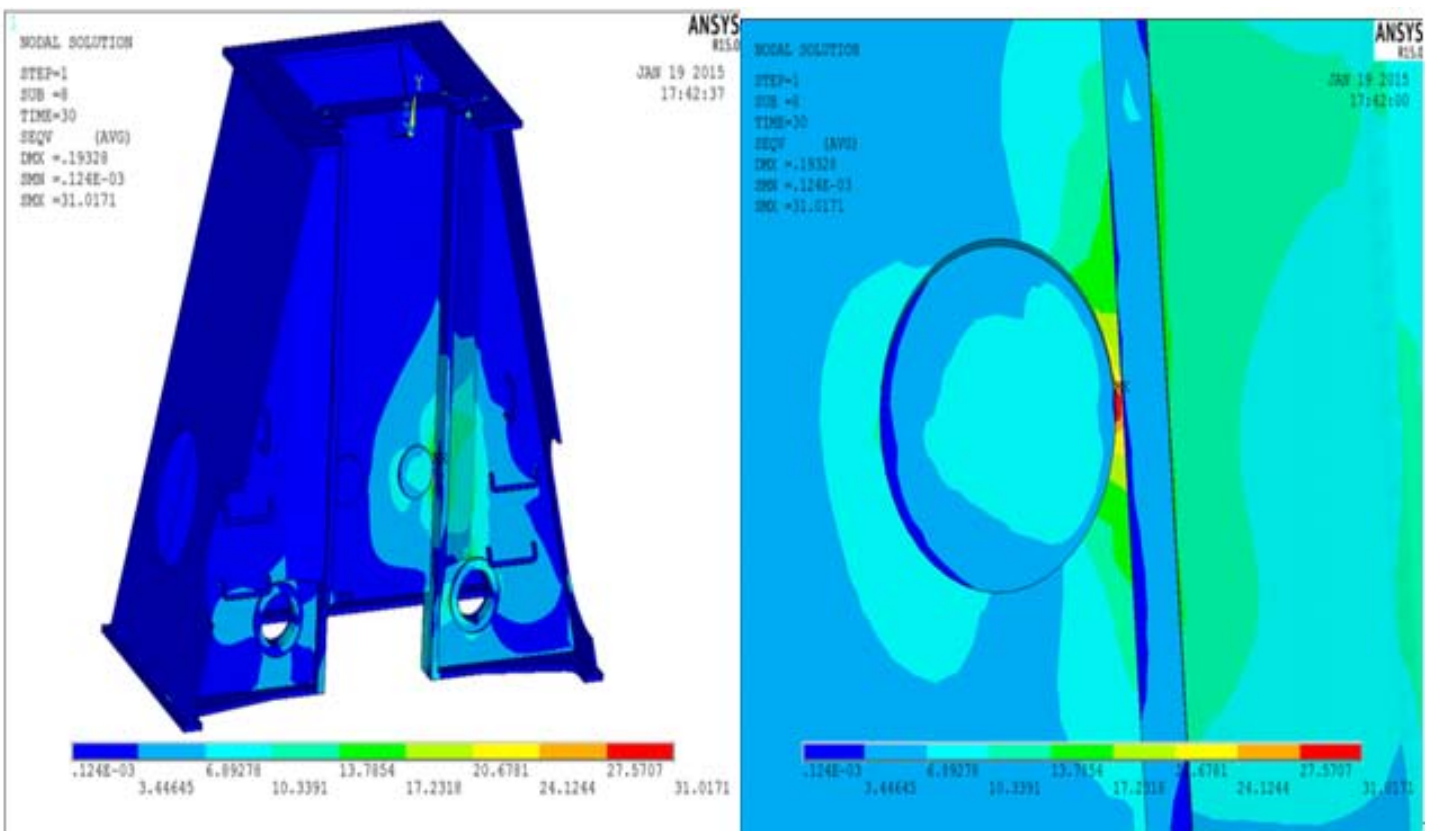




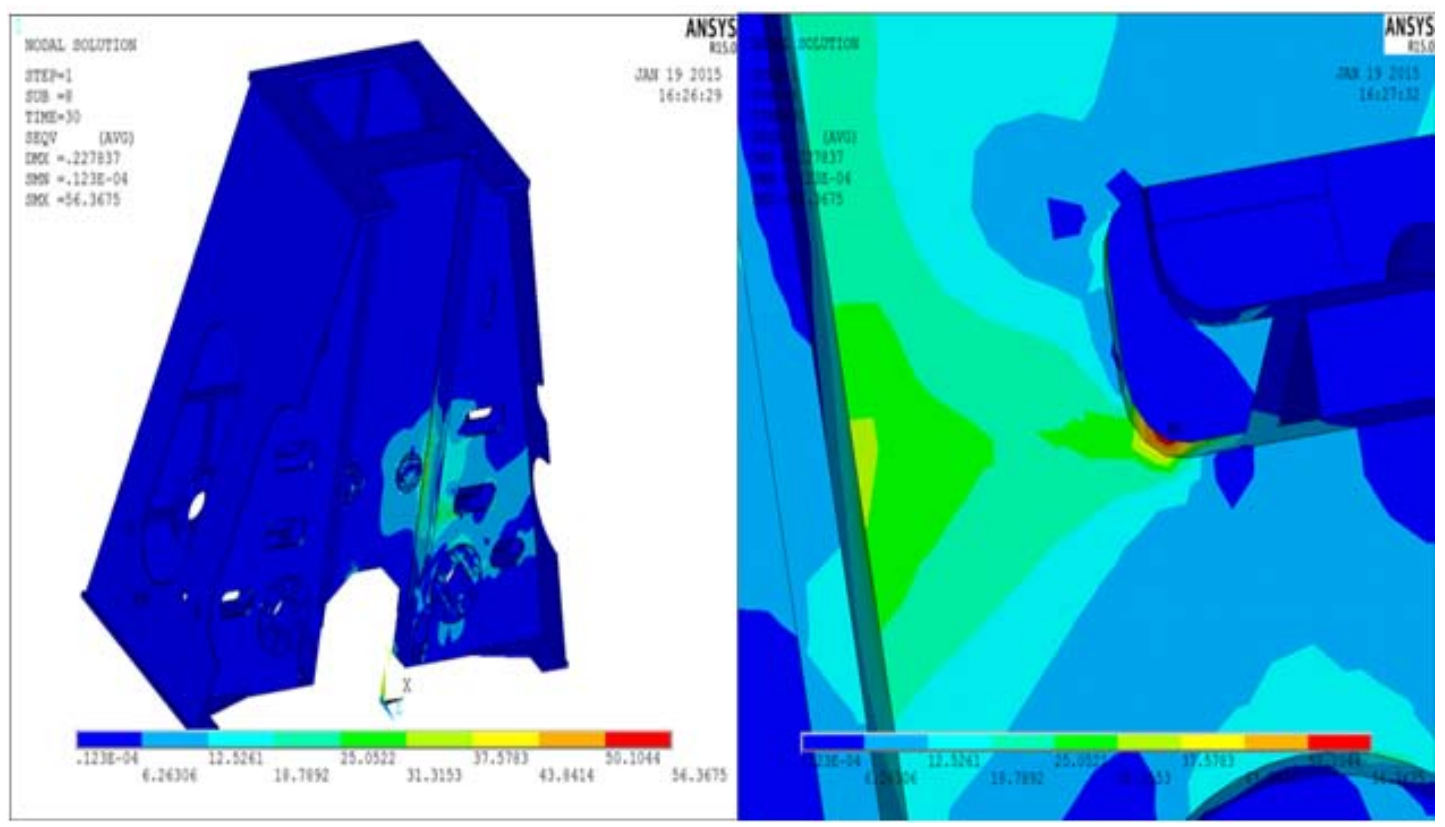

Figure 7. Comparison of stress distribution of different frame structures

Figure 7 is the comparison of stress distribution. Stress distribution are similar in two structures. Stress concentration appears on the pressure side, but the area of the region and the stress value are different. In addition, the area of stress in the latter structure is smaller, this is because the double-butterfly plate is beneficial to enhancing the bearing capacity.

By analyzing the results at two different moments, maximum positive and negative lateral force, a conclusion can be drawn that the strength and rigidness of the frame is satisfying. Attention should be paid to the areas where stress concentration appears, because fatigue damage is likely to appear on these areas.

\section{Effect rule of bearing force to the strength of frame diaphragm plate}

The frame analyzed in this paper have holes on the butterfly plate to install bearing seats. Compared to the tradition frames, it has to bear the periodical pressure of the balancing equipment during working, so it is necessary to perform finite element analysis in this kind of frame diaphragm plate.

The structure of the frame is simplified. The simplified model is shown in figure 8 .
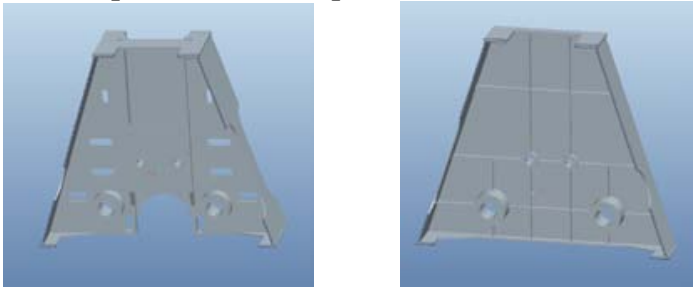

Figure 8. Simplified frame model

The curve charts of bearing force are shown in figure 9 and 10. Four moments were chosen to perform the analysis, and pressure was applied on the $120^{\circ}$ area plain bearing bore. 


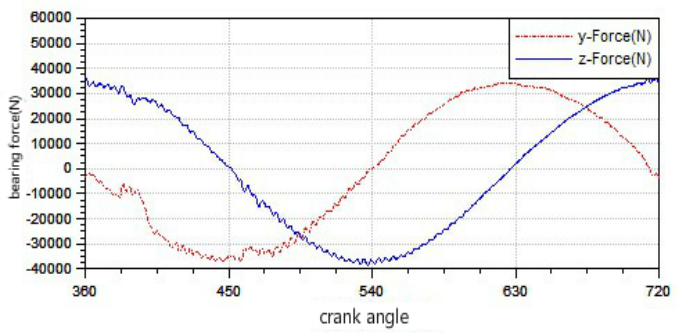

Figure 9. Bearing force on the middle and top plate of the frame

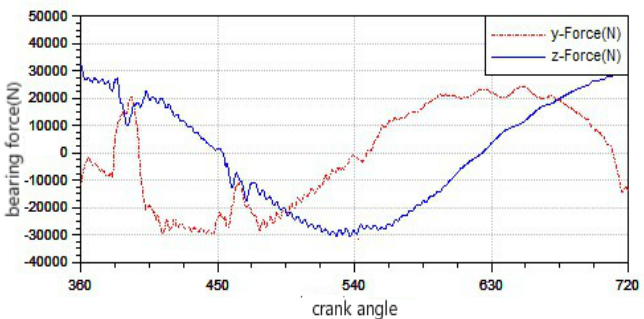

Figure 10. Bearing force on the top plate of the frame

\subsection{The moment when the piston is at the TDC}

At this moment, balance weight is at the bottom position. The distribution of deformation and stress of the frame is shown in figure 11 and 12.

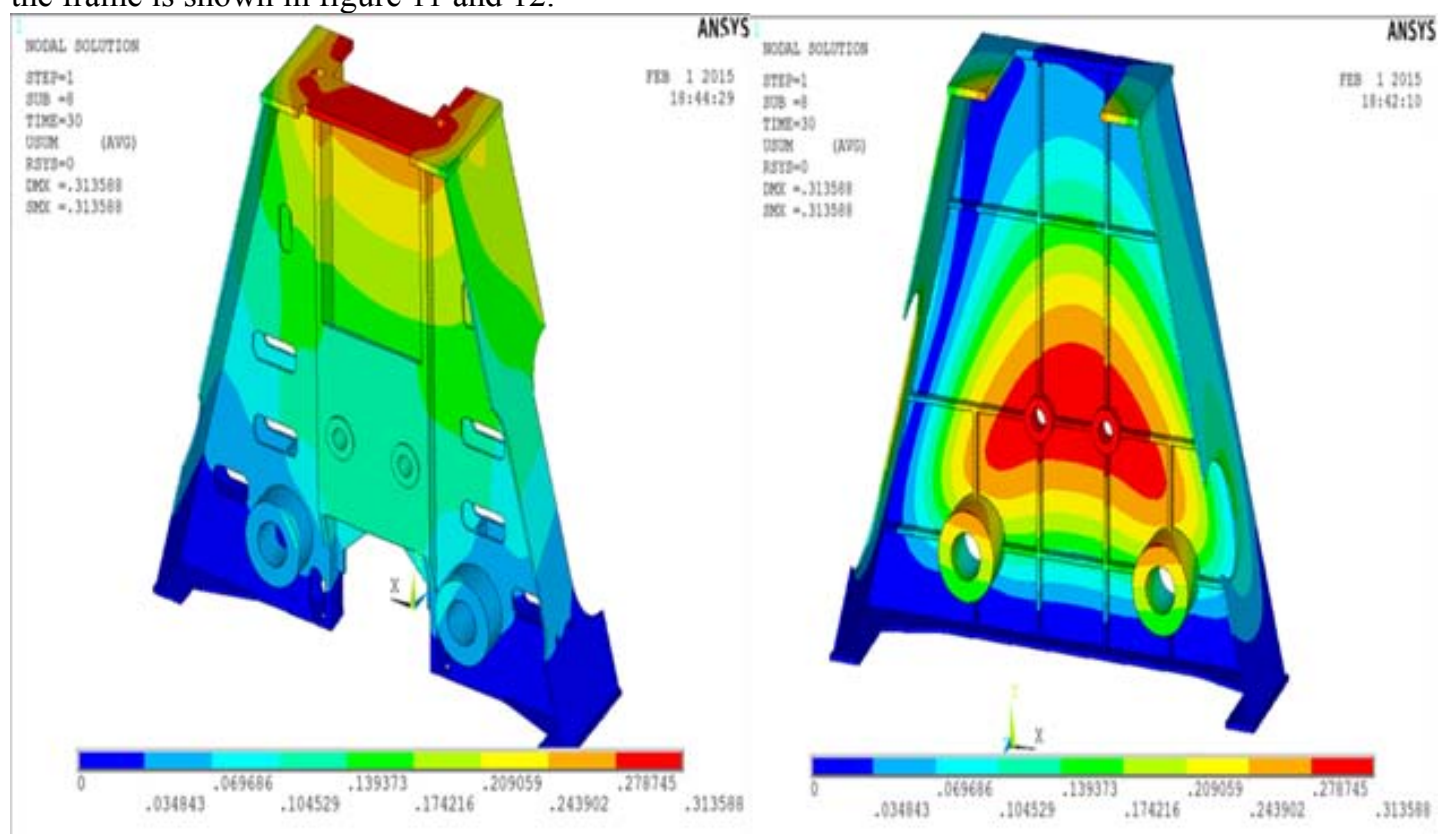

Figure 11. Deformation distribution of the frame 

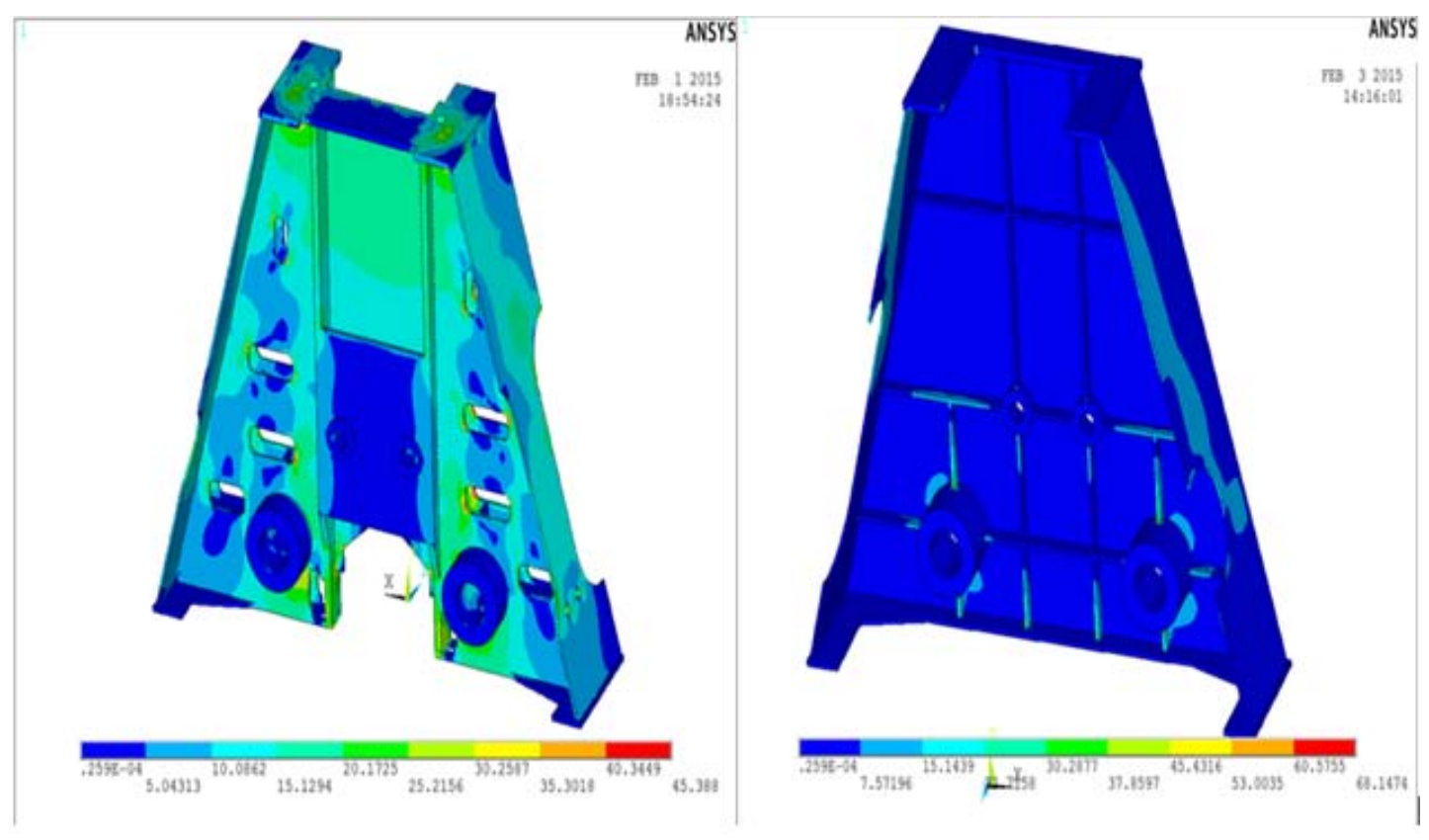

Figure 12. Stress distribution of the frame

As shown in figure 11, the maximum deformation of the middle diaphragm plate appears on the top of the frame, which is $0.314 \mathrm{~mm}$, while the maximum deformation of the side plate is also $0.314 \mathrm{~mm}$, which appears in the middle. Deformation around two smaller bearing block holes are different, and the side diaphragm plate one is larger than that on the middle diaphragm plate.

As shown in figure 12, the stress on the frame concentrates on the middle diaphragm plate, while little stress distributes on side plates, which mainly concentrates around the bearing holes. This is because the middle diaphragm plate bears pretightening forces of the bolts and gas pressure, while the side plates mainly bears the bearing force.

\subsection{The moment when the piston is at $90^{\circ}$ after the TDC}

At this moment, balance weight is at the horizontal position. The distribution of deformation and stress of the frame is shown in figure 13 and 14.
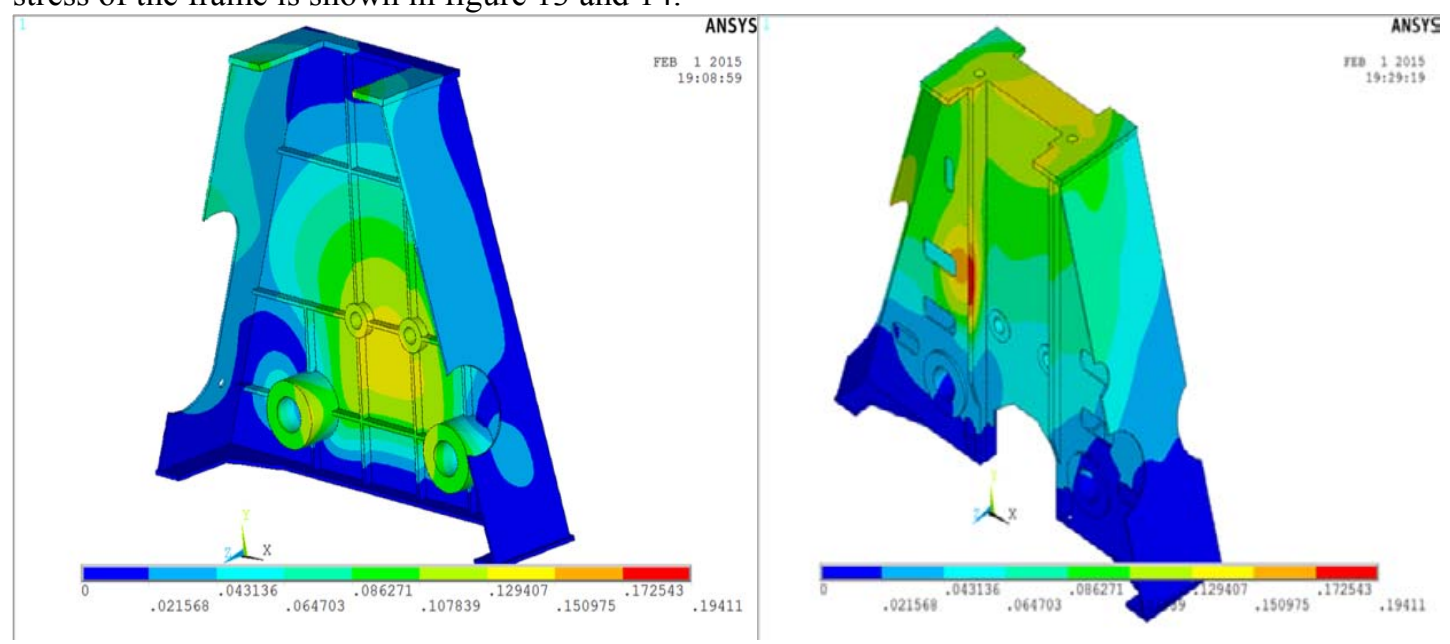

Figure 13. Deformation distribution of the frame 
The maximum deformation appears unsymmetrically on the edge, which is $0.194 \mathrm{~mm}$. The region of deformation concentrates on two small bearing holes, which is $0.124 \mathrm{~mm}$. The deformation around the bearing holes of the middle diaphragm plate is larger than that around the side plate.
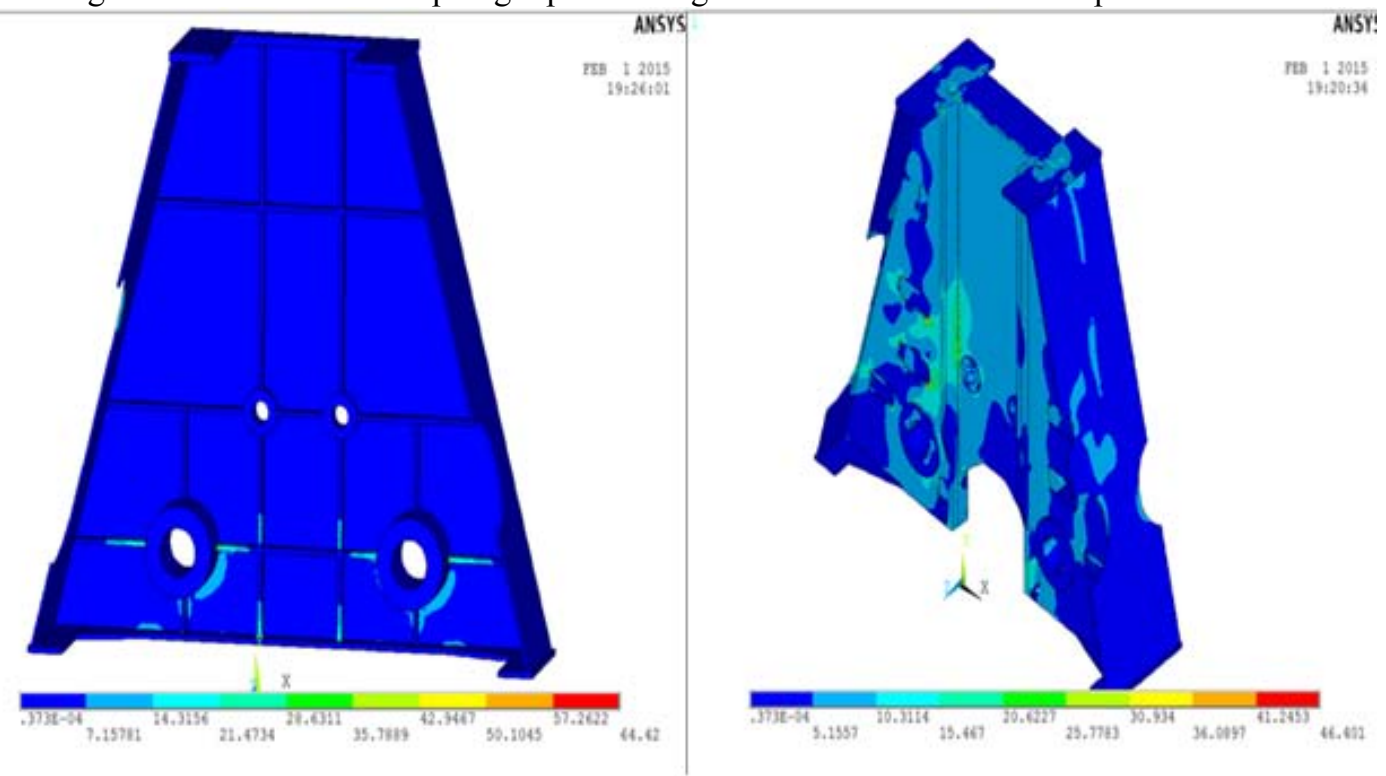

Figure 14. Stress distribution of the frame

As shown in figure 14, stress on the frame at this moment is not large, the largest stress appears on the diaphragm plate, which is less than $60 \mathrm{MPa}$, is much smaller than the allowable stress of the material. On the side plate, stress concentrates on the pressure side, while stress of other regions is nearly 0 .

\subsection{The moment when the piston is at the BDC}

At this moment, balance weight is at the top position. The distribution of deformation and stress of the frame is shown in figure 15 and 16.
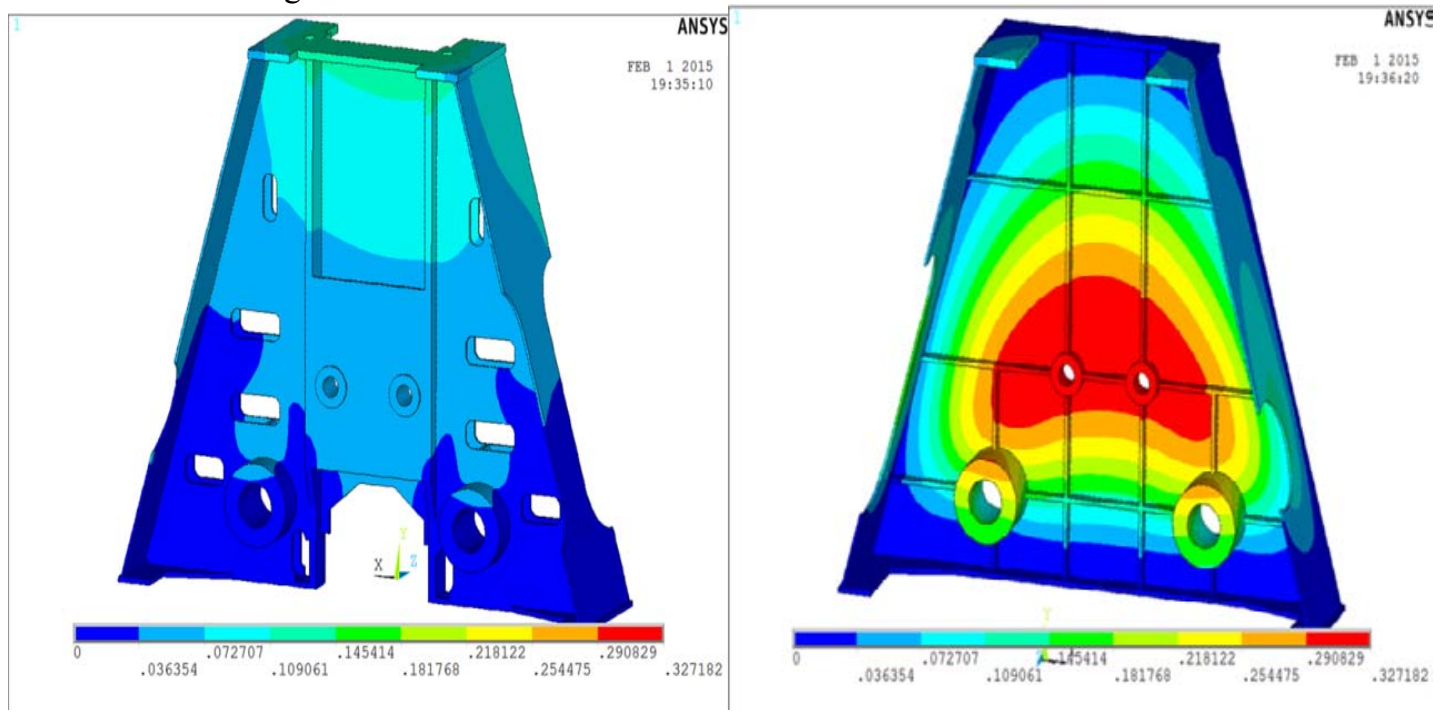

Figure 15. Deformation distribution of the frame 

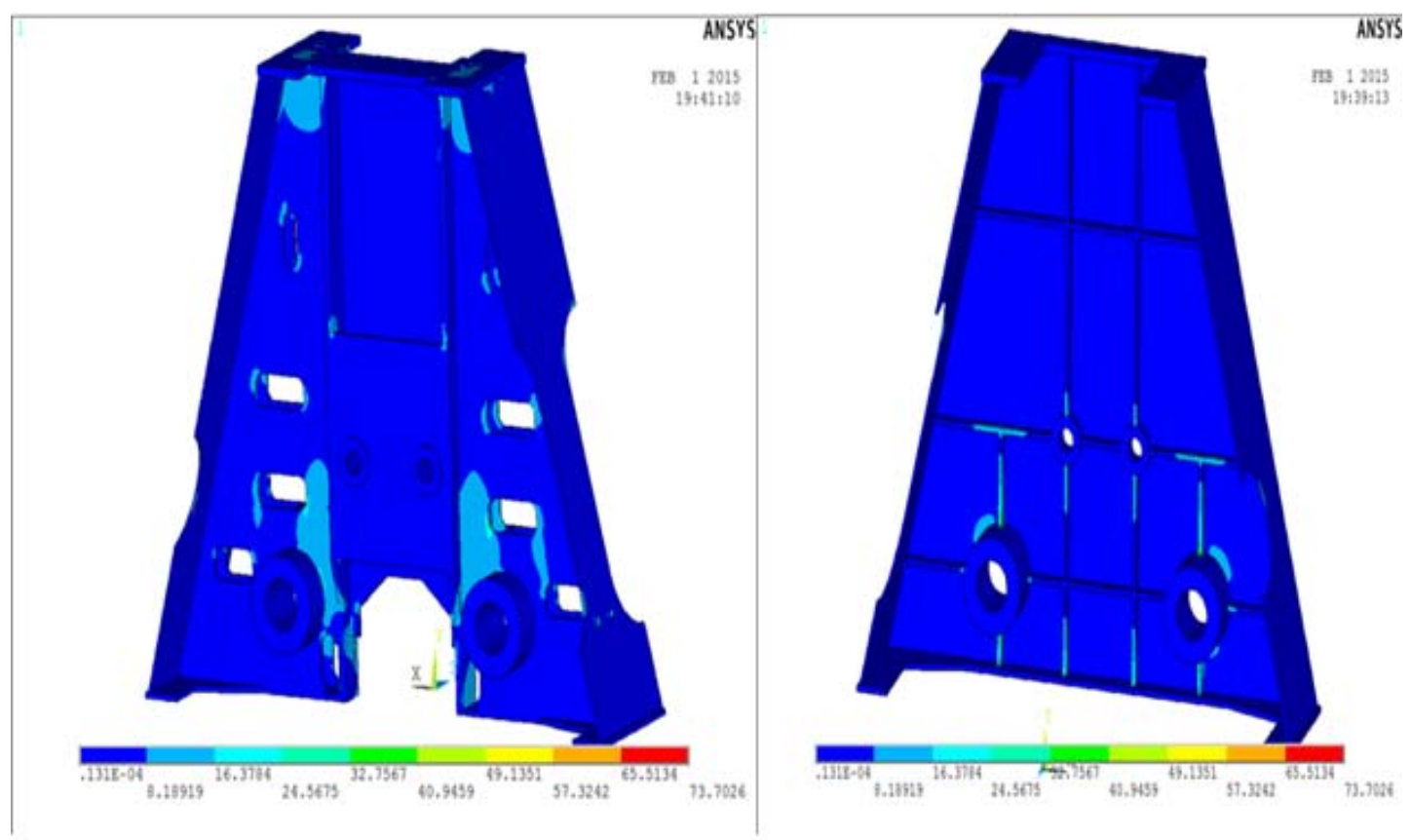

Figure 16. Stress distribution of the frame

The maximum deformation areas are close to the two smaller bearing block holes, and the maximum deformation is $0.327 \mathrm{~mm}$. A conclusion can be drawn that double-butterfly plate structure can prevent the frame from distortion effectively. As shown in figure 16, at this moment, stress on the frame is nearly 0 , which is mainly because gas pressure counteracts some part of bearing loads.

\subsection{The moment when the piston is at $90^{\circ}$ after the TDC}

At this moment, balance weight is at the other horizontal position. The distribution of deformation and stress of the frame is shown in figure 17 and 18.
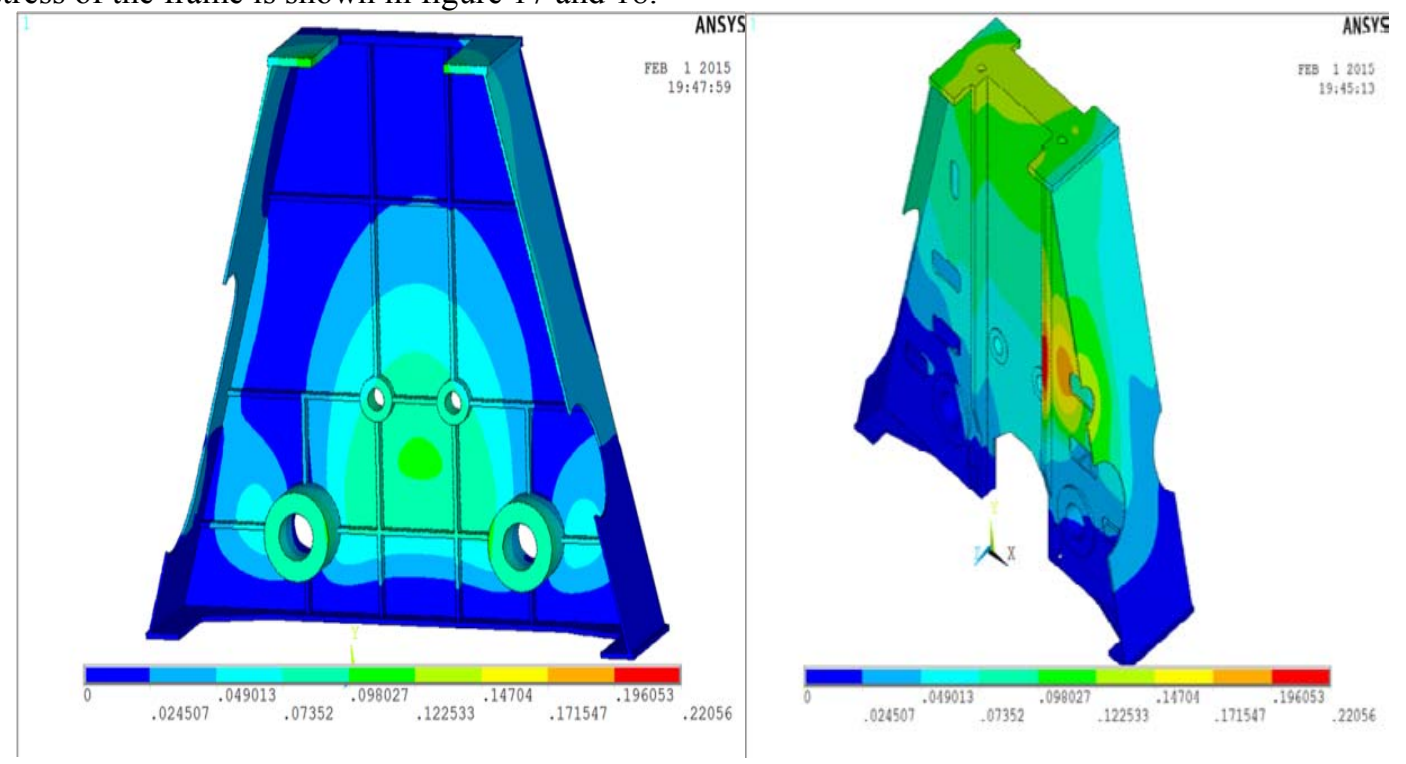

Figure 17. Deformation distribution of the frame 
The maximum deformation area is the edge of crosshead slide guide, and the value is $0.221 \mathrm{~mm}$. Deformation of frame diaphragm is unsymmetrical. However, the distribution of deformation of side diaphragm plate is almost symmetrical, this is because forces on two bearing holes are equal in value and opposite in direction. The maximum deformation in side diaphragm plate is $0.141 \mathrm{~mm}$.
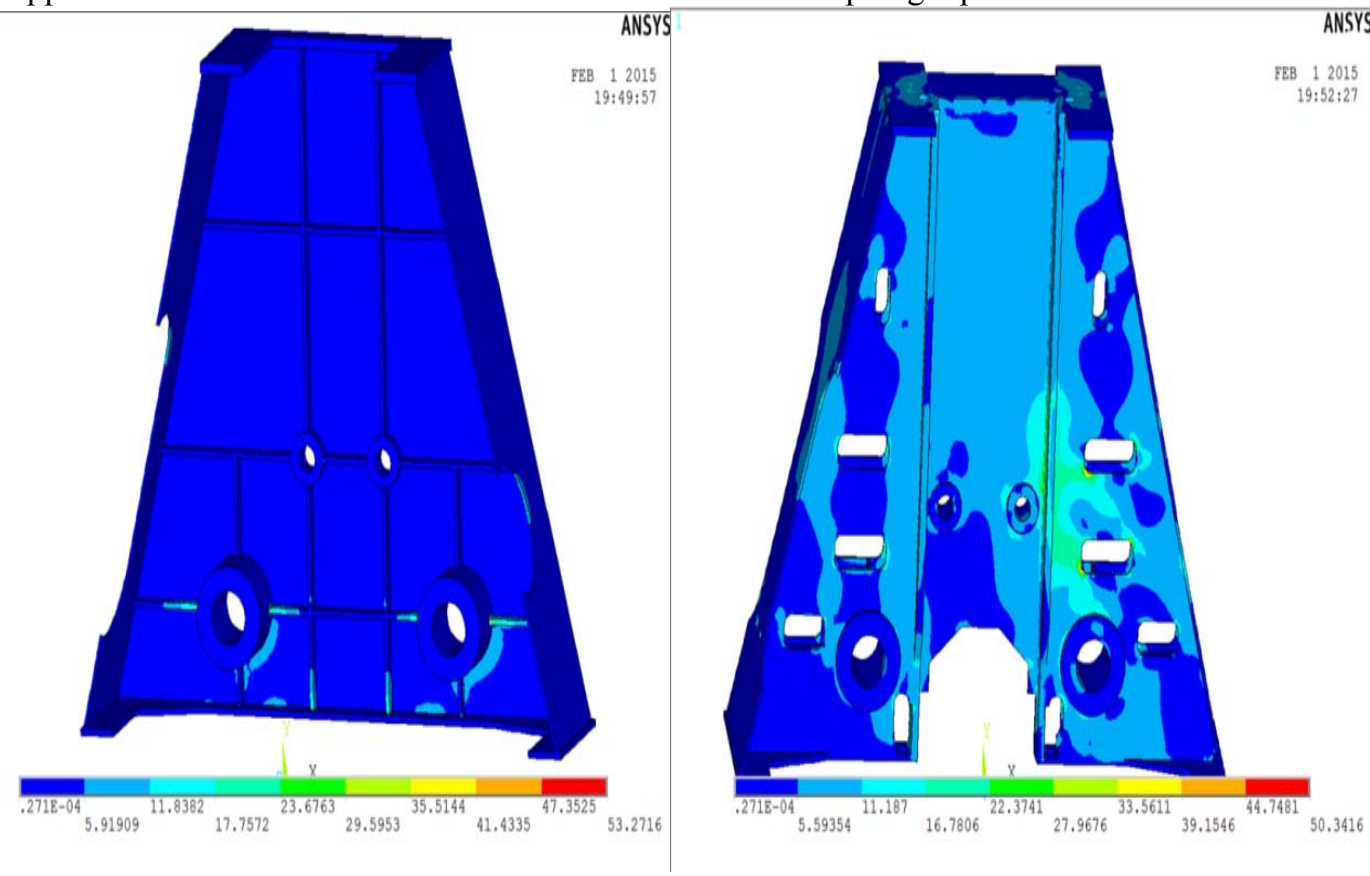

Figure 18. Stress distribution of the frame

The range of stress distribution on the middle diaphragm plate is wide because it is the main bearing block. Stress is distributed obviously around the crosshead slide and the bearing holes, but their values are not very large (less than $30 \mathrm{MPa}$ ). Stress on the side plate is small in general.

\section{Conclusions}

By comparing the chart of distribution of stress and deformation of two different structures, some advantages of the improved structure can be found: Firstly, double-butterfly plate can to some extent improve the carrying capacity of the frame; secondly, it is beneficial to assemble and test the balancing system, and reduce the difficulty in processing bearing house holes on the frame. But as to the crosshead slide guide, the triangle supporting structure of single-butterfly plate can reduce deformation to an extreme extent.

By analyzing four different moments, it is found that when the piston is at the TDC and BDC, deformation of side plate is the largest, and the maximum value is $0.33 \mathrm{~mm}$, while at other moments frame's deformation is small, which is under $0.15 \mathrm{~mm}$. This indicates that frame has a good ability to resist deformation. By comparing the side plate and the middle diaphragm plate, it can be known that double-butterfly plate can improve the ability to resist deformation.

\section{References}

1. Jun SUN, Chang-lin GUI, Jing-feng WANG, Study on Calculation of Crankshaft Deformation and Bearing Load Based on Whole Crankshaft Beam-element Method, Transactions of the Chinese Society for Agricultural Machinery, 2007, 06:6-9.

2. Da-rong CHEN, Design of marine internal combustion engine, (First Edition), Beijing, Press of 
National Defence Industry, 1995.

3. Gui-xin WANG, Wu XU, Hua-zhong HU, et al, Strength Analysis of a Connecting Rod Based on the Three-dimensional Contact Finite Element Method and Its Experimental Verification, Journal of Engineering for Thermal Energy \& Power, 2013,02:121-125+213.

4. Xiao-jun XU, Analysis for Dynamic Characteristics of a Diesel Engine Crankshaft System, Harbin, Master degree thesis of Harbin Engineering University, 2011.

5. Xue-xian Wang, The Kinematics and Dynamics Analysis and Simulation for Crank Link Mechanism in 41028 Diesel Engineer, Dalian, Master degree thesis of Dalian Jiaotong University, 2007.

6. E.Tolga Duran, ACagrl Sever, Dynamic Simulation and Endurance Limit Safety Factor Calculation for Crankshaft-Comparison of Single Mass and Dual Mass Flywheel, SAE 2008-01-2622, 2008.

7. Xian-qi YANG, Xiao-ling LI, The modern theory of finite element technology and engineering application, Beijing, Beihang University Press, 2007.

8. Li-ying XIE, Study on Bending Fatigue Test of Automotive Engine Crankshaft, Automobile Technology \& Material, 2006, (3):9-12 